\title{
The timing of optimal capital income tax reforms: the role of intangible capital investment
}

\author{
Juan Carlos Conesa ${ }^{1}$ - Begoña Domínguez ${ }^{2}$
}

Received: 11 February 2019 / Accepted: 3 July 2019 / Published online: 16 July 2019

(c) The Author(s) 2019

\begin{abstract}
This paper studies the role of intangible capital investment in the timing of optimal capital income tax reforms. Within an infinitely lived worker-capitalist model as in Judd (J Public Econ 28:59-83, 1985), we consider two different economies: one in which capitalists devote physical investment, management time and intangible capital investment to build capital; and a second one in which capitalists do not need to devote intangible capital investment. We perform a Pareto-improving Ramsey tax reform and compare the optimal paths of corporate and dividend taxes during the transition with and without intangible capital. Without intangible investment, optimal corporate income taxes are set at $100 \%$ for 10 years and then fall to $0 \%$, while optimal dividend taxes are set to $78 \%$ initially and follow a steep decline to $37 \%$ over 10 years. With intangible investment, optimal corporate income taxes are set to $-20 \%$ initially and slowly converge toward zero, while dividend income taxes are set to $61 \%$ initially and follow a slow decline to $27 \%$ over 50 years.
\end{abstract}

Keywords Optimal policy · Capital taxes · Intangible investment

JEL Classification E62 $\cdot \mathrm{H} 23 \cdot \mathrm{H} 25$

\section{Introduction}

In this paper, we evaluate the impact that the existence of intangible investment has for the outcome of optimal capital income tax reforms in an environment where redistribu-

$凶$ Juan Carlos Conesa

juan.conesa@stonybrook.edu

Begoña Domínguez

b.dominguez@uq.edu.au

1 Department of Economics, Stony Brook University, Stony Brook, NY 11794, USA

2 School of Economics, The University of Queensland, Colin Clark Building (39), St Lucia, Brisbane, QLD 4072, Australia 
tive concerns matter. We consider an infinitely-lived two-agent model, where workers provide labor to firms, while firms are run by capitalists that invest tangible and intangible resources, and provide management time in order to build productive capital. We consider two forms of capital taxation: corporate taxes and dividend taxes. The key difference between these forms of taxation lies in their differential tax treatment. Tangible investment is tax deductible from dividend income taxation, while this is not the case for corporate income taxes. In contrast, intangible investment is immediately expensed and then tax deductible from both corporate and dividend income taxation.

Intangible investment by firms includes explicit expenses like R\&D, IT, or marketing. Besides those explicit investments, there are additional expenses or allocation of resources by firms that contribute toward building a company's reputation and market value, such as building and maintaining a customer base, training and maintaining the labor force, etc. We distinguish between two types of such allocation of resources. When we think of the allocation of explicit resources, we refer to it as intangible investment, and when we think of the allocation of hours of work, we refer to it as managerial time. The expenses in intangible investment are large and have been found to be important for productivity and hours, see McGrattan and Prescott (2005). Managerial time is also large, given the fraction of total hours worked in non-production activities. Conesa and Domínguez (2013) study optimal capital and labor taxes in a representative agent economy, as in Chamley (1986), and find that intangible investment matters for the optimal tax prescriptions and for the time inconsistency of optimal tax reforms. While Conesa and Domínguez (2018) already add redistributive concerns to the analysis, in this paper we focus on the role of intangible investment for the timing of optimal capital taxes.

In this environment, we perform a Pareto-improving Ramsey tax reform. We characterize the resulting optimal paths of corporate and dividend taxes and compare them with those for an economy with no intangible investment. Our main results are as follows. Without intangible investment, the Ramsey corporate income tax is set at its maximum (we assume it is $100 \%$ ) for the first 10 years and then set to zero permanently, while the Ramsey dividend tax rate is set to $78 \%$ in period 0 and steeply declines to $37 \%$ over the first 10 years. With intangible investment, the optimal capital tax prescriptions change substantially. As expected, the presence of intangible investment limits the ability of the tax authority to confiscate initial wealth through high corporate income taxes. The Ramsey corporate income tax rate falls on impact to $-20 \%$ in period 0 and converges very slowly toward zero. The Ramsey dividend income tax rate is set to $61 \%$ and declines also very slowly toward $27 \%$. The overall transition takes around 50 years. Intangible investment does not affect the timing of optimal labor tax rates but affects the level. Without intangible investment, optimal labor tax rates are roughly zero, while with intangible investment, optimal labor tax rates are about $13 \%$. Overall, the presence of intangible capital decreases substantially the magnitude of income redistribution, not only in the short run but also in the long run.

Following up with the public finance tradition (see Auerbach 2002), there are a number of papers that consider different forms of capital taxation and tax deductions. Abel (2007) studies optimal capital taxes with tax deductible purchases. Anagnostopoulos et al. (2012) study the effect of dividend and capital gains tax cuts in an 
incomplete market model. Strulik and Trimborn (2012) also consider these forms of taxation when performing a dynamic scoring exercise.

Other papers also examine optimal policy in similar heterogeneous agent economies. Armenter (2007) studies Markov-perfect time-consistent optimal policies in a similar environment. Bassetto (2014) studies optimal policy in an economy with rentiers and tax payers. The above papers, however, do not consider intangible investments.

The role of intangibles has not been widely studied. Recently, Lev (2018) points at the continued growth of intangible investments as the key characteristic of developed economies. A recent paper by Peters and Taylor (2017) finds that intangible capital adjusts more slowly to changes in investment opportunities. This may explain our finding of Ramsey reforms with a longer transition in the presence of intangible investment.

The rest of the paper is organized as follows. Section 2 presents the model economy. Section 3 describes the optimal policy problem and develops the main analytical and numerical results. Section 4 concludes. The appendix includes further derivations.

\section{The model}

In this section we present our general model economy. Our benchmark model extends the framework of Conesa and Domínguez (2018) by incorporating intangible investment.

Time is discrete and denoted by $t$, with $t=0,1,2, \ldots$ As in Judd (1985), the economy is populated by a benevolent government and two types of infinitely-lived agents: capitalists and workers. All agents are identical within type. Workers (agents of type 1) supply labor to firms and cannot save. Capitalists (agents of type 2) own firms and can save. ${ }^{1}$ In addition, capitalists dedicate management time and intangible investment to the firm in order to build new capital. Population is normalized to one and is composed of a proportion $\kappa_{1}$ of workers and a proportion $\kappa_{2}=1-\kappa_{1}$ of capitalists.

We now describe the representative worker. Given the discount factor $\beta \in(0,1)$, the worker's preferences are given by

$$
U_{1}=\sum_{t=0}^{\infty} \beta^{t} u_{1}\left(c_{1, t}, n_{1, t}\right),
$$

where $c_{1, t}$ denotes the worker's consumption, and $n_{1, t}$ the quantity of labor supplied. The utility function $u_{1}$ satisfies standard conditions; i.e., $u_{1}$ is assumed to be strictly increasing (decreasing) in consumption (labor), strictly concave (convex) in consumption (labor), and twice continuously differentiable. For simplicity of exposition, we assume $u_{1}$ to be separable between consumption and labor. In any given period $t$, the budget constraint of the representative worker is given by

\footnotetext{
1 As in Conesa and Domínguez (2018), capitalists may choose to supply raw labor instead of or in addition to managerial effort. For Pareto-improving reforms in our benchmark parameterization, this option is irrelevant. However, this option matters for Pareto weights on the capitalists that are very low, see our sensitivity analysis.
} 


$$
c_{1, t}=\left(1-\tau_{t}^{n}\right) w_{t} n_{1, t},
$$

where wages are denoted by $w_{t}$ and labor income tax rates by $\tau_{t}^{n}$.

The optimization problem of the representative worker is as follows. Given policies, prices and other agents' choices, each worker chooses $\left\{c_{1, t}, n_{1, t}\right\}_{t=0}^{\infty}$ to maximize her welfare (1) subject to her budget constraint (2). This problem yields the following optimal consumption-labor decision:

$$
-u_{1 n, t}=u_{1 c, t}\left(1-\tau_{t}^{n}\right) w_{t} .
$$

In the above equation and in what follows, we denote partial derivatives with a subscript.

We now turn to describe the representative capitalist. The capitalist's preferences are given by

$$
U_{2}=\sum_{t=0}^{\infty} \beta^{t} u_{2}\left(c_{2, t}, e_{2, t}\right)
$$

where $c_{2, t}$ denotes the capitalist's consumption, and $e_{2, t}$ is the quantity of management time supplied. We assume that the utility function $u_{2}$ satisfies the same general properties as $u_{1}$. Each capitalist owns an equal amount of capital $k_{t}>0$ and employs an equal amount of labor $n_{t}=\left(\frac{\kappa_{1}}{\kappa_{2}}\right) n_{1, t}$, to run a firm that produces a general consumption/investment good using the technology $f\left(k_{t}, n_{t}\right)$, where $f$ is increasing, concave and satisfies the Inada conditions. In any period $t$, the budget constraint of the representative capitalist is given by:

$$
c_{2, t}+b_{t+1}=\Pi_{t}+R_{t}^{b} b_{t}
$$

where $b_{t+1}$ denotes government bond purchases, $R_{t}^{b}$ the return on government bonds and $\Pi_{t}$ the after-tax dividend income, which takes the form:

$$
\Pi_{t}=\left(1-\tau_{t}^{d}\right)\left[\left(1-\tau_{t}^{k}\right)\left[f\left(k_{t}, n_{t}\right)-w_{t} n_{t}-x_{u, t}\right]+\tau_{t}^{k} \delta k_{t}-x_{m, t}\right] .
$$

Dividend income $\Pi_{t}$ is taxed at the rate $\tau_{t}^{d}$. Dividend income includes corporate income, $f\left(k_{t}, n_{t}\right)-w_{t} n_{t}-x_{u, t}$, that is taxed at the rate $\tau_{t}^{k}$. Notice that there is a capital depreciation allowance equal to the depreciation of the capital stock and that the only source of tangible investment is retained earnings. Capitalists can invest in both tangible $x_{m, t}$ and intangible investments $x_{u, t}$. Tangible investment is fully and immediately tax deductible from dividend income but not from corporate income, while intangible investment is fully and immediately tax deductible for all forms of income. These two forms of investments, together with management time, are required in order to produce new capital ${ }^{2}$ :

$$
k_{t+1}=I\left(x_{m, t}, x_{u, t}, e_{2, t}\right)+(1-\delta) k_{t} .
$$

\footnotetext{
2 Here we think of capital as a composite that reflects overall productive capacity and would equal the value of the firm in equilibrium. This simplifies the analysis substantially. In Conesa and Domínguez (2013), instead, we kept track of two different types of capital.
} 
The function $I$ is assumed to be increasing, concave, homogeneous of degree 1, continuously differentiable, and satisfies the Inada conditions. In equation (7), we assume that intangible investments $x_{u, t}$ and managerial time are necessary to transform tangible resources into new productive capital $k_{t}$. Later on, we will be comparing this situation with an economy where intangible investments are not required, that is, where $I\left(x_{m, t}, x_{u, t}, e_{2, t}\right)=I\left(x_{m, t}, e_{2, t}\right)$.

Given policies, prices and other agents' choices, a capitalist chooses $\left\{c_{2, t}, e_{2, t}, x_{m, t}\right.$, $\left.x_{u, t}, n_{t}, k_{t+1}, b_{t+1}\right\}_{t=0}^{\infty}$ to maximize her welfare (4) subject to her budget constraint (5), the technology for new capital (7), and the no-Ponzi game conditions on capital and bonds. The optimality conditions for this problem are given by

$$
\begin{aligned}
& {\left[c_{2, t}\right]} \\
& {\left[e_{2, t}\right]} \\
& {\left[x_{m, t}\right]} \\
& {\left[x_{u, t}\right]} \\
& {\left[n_{t}\right]} \\
& {\left[k_{t+1}\right]} \\
& {\left[b_{t+1}\right]}
\end{aligned}
$$

$$
\begin{aligned}
u_{2 c, t} & =\xi_{t}, \\
-u_{2 e, t} & =I_{e, t} \varphi_{t}, \\
\varphi_{t} I_{m, t} & =\left(1-\tau_{t}^{d}\right) \xi_{t}, \\
\varphi_{t} I_{u, t} & =\left(1-\tau_{t}^{d}\right)\left(1-\tau_{t}^{k}\right) \xi_{t}, \\
f_{n, t} & =w_{t}, \\
\varphi_{t} & =\beta \xi_{t+1}\left[1+\left(1-\tau_{t+1}^{k}\right)\left(r_{t+1}-\delta\right)\right]+\beta \varphi_{t+1}, \\
\xi_{t} & =\beta \xi_{t+1} R_{t+1}^{b},
\end{aligned}
$$

and the transversality conditions, where $\xi_{t}$ and $\varphi_{t}$ denote the multipliers on (5) and (7), respectively. The above optimality conditions can be summarized in a non-arbitrage condition on bonds, the labor hiring decision $f_{n, t}=w_{t}$, and

$$
\begin{aligned}
-\frac{u_{2 e, t}}{I_{e, t}}= & \left(1-\tau_{t}^{d}\right) \frac{u_{2 c, t}}{I_{m, t}} \\
I_{u, t}= & \left(1-\tau_{t}^{k}\right) I_{m, t}, \\
\left(1-\tau_{t}^{d}\right) \frac{u_{2 c, t}}{I_{m, t}}= & \beta\left(1-\tau_{t+1}^{d}\right)\left[I_{m, t+1}\left[\left(1-\tau_{t+1}^{k}\right)\left(f_{k, t+1}-\delta\right)+\delta\right]\right. \\
& +(1-\delta)] \frac{u_{2 c, t+1}}{I_{m, t+1}} .
\end{aligned}
$$

From the above equations, we see that dividend taxes distort management time and the timing of investment, while corporate taxes distort the intra-period allocation of investment between tangibles and intangibles, and the intertemporal decision to invest. Notice that in the absence of managerial effort a constant dividend tax would not be distortionary, and as such it could be used to confiscate as much of initial wealth as desired.

Substituting dividend and corporate taxes from the first two optimality conditions, the Euler condition (10) can be written as

$$
-\frac{u_{2 e, t}}{I_{e, t}}=-\beta\left[I_{u, t+1}\left(f_{k, t+1}-\delta\right)+I_{m, t+1} \delta+(1-\delta)\right] \frac{u_{2 e, t+1}}{I_{e, t+1}} .
$$


The government is benevolent with preferences given by

$$
\gamma_{1} \kappa_{1} U_{1}+\gamma_{2} \kappa_{2} U_{2}
$$

where $\gamma_{1}$ is the Pareto weight on workers and $\gamma_{2}=1-\gamma_{1}$ on capitalists. The government must finance an exogenous and wasteful government consumption, $g_{t}>0$, per period and the debt repayments through taxes and new bond issuance. We assume the present value of all government expenditures and liabilities is large enough to require distortionary taxation and low enough to guarantee that the Ramsey allocation converges to an interior steady state. ${ }^{3}$ In each period $t$, the government's budget constraint is given by

$$
\begin{aligned}
& \kappa_{1} \tau_{t}^{n} w_{t} n_{1, t}+\kappa_{2}\left[\tau_{t}^{k}\left(1-\tau_{t}^{d}\right)\left(f_{k, t} k_{t}-x_{u, t}-\delta k_{t}\right)\right. \\
& \left.+\tau_{t}^{d}\left(f_{k, t} k_{t}-x_{u, t}-x_{m, t}\right)+b_{t+1}\right] \\
& \quad=g_{t}+\kappa_{2} R_{t}^{b} b_{t},
\end{aligned}
$$

where corporate tax rates are bounded above by $100 \%, \tau_{t}^{k} \leq 1$, in all periods.

Finally, the resource constraint of the economy is

$$
\kappa_{1} c_{1, t}+\kappa_{2} c_{2, t}+\kappa_{2}\left(x_{m, t}+x_{u, t}\right)+g_{t}=\kappa_{2} f\left(k_{t}, n_{t}\right) .
$$

For a given policy and initial conditions, the competitive equilibrium of this economy is characterized by the budget constraint and the optimality condition for the workers, (2)-(3), the budget constraint and optimal conditions for the capitalists, (5)-(10), $f_{n, t}=w_{t}$, and the non-arbitrage condition on bonds, together with feasibility (13), market clearing and the transversality conditions.

\section{The Ramsey tax reform}

This section performs a Ramsey tax reform in our economy. We first present the Ramsey problem by the government at date 0 , next characterize the Ramsey tax plan analytically, and then we resort to numerical methods. As usual in this literature, we assume that there is a commitment technology so that future governments follow the Ramsey policy plan prescribed by the government in period 0 . In addition, we assume that the initial after-tax interest rate on bonds $R_{0}^{b}$ is given.

Here we follow the primal approach and use the workers' and capitalists' optimality conditions to substitute prices and taxes in their respective budget constraints. As a

\footnotetext{
3 Recently, Straub and Werning (2018) re-examine Judd (1985) and Chamley (1986)'s results. They find that the optimal capital tax rate maybe set at the upper bound forever whenever the intertemporal elasticity of substitution is less than one and the initial government debt is large enough. As mentioned by the authors, they do not allow for consumption taxes [as considered by Chari et al. (2016)] and dividend taxes with tax deductible investment [as considered in Conesa and Domínguez (2018) and in this paper], since these instruments provide alternative ways to tax initial wealth.
} 
result and as shown in the "Appendix", we obtain the following implementability conditions:

$$
u_{1 c, t} c_{1, t}+u_{1 n, t} n_{1, t}=0
$$

for the worker in each period, and

$$
\sum_{t=0}^{\infty} \beta^{t}\left[u_{2 c, t} c_{2 t}+u_{2 e, t} e_{2, t}\right]=W_{0}
$$

for the capitalist in its life-time, where

$$
W_{0}=-\frac{u_{2 e, 0}}{I_{e, 0}}\left[I_{m, 0}\left[\frac{I_{u, 0}}{I_{m, 0}}\left(f_{k, 0}-\delta\right)+\delta\right]+(1-\delta)\right] k_{0}+u_{2 c, 0} R_{0}^{b} b_{0} .
$$

In addition, the upper bound on capital tax rates can be written in period 0 as $\frac{I_{u, 0}}{I_{m, 0}} \geq 0$ and in each period $t \geq 1$ as

$$
-\frac{u_{2 e, t-1}}{I_{e, t-1}} \geq-\beta\left[I_{m, t} \delta+(1-\delta)\right] \frac{u_{2 e, t}}{I_{e, t}} .
$$

For a given allocation, labor tax rates follow from (3). However, for the capitalists, we have three optimality conditions (8)-(10) as functions of two taxes: the dividend and corporate tax rates. These tax rates follow, respectively, from (8) and (9). Then, in our economy with intangible investment, an allocation needs to additionally satisfy the Euler condition (10), which takes the form of the decentralization condition after substituting taxes (11).

The Ramsey problem is defined as follows: Given the exogenous stream of government spending $\left\{g_{t}\right\}_{t=0}^{\infty}$ and initial conditions for capital, bonds and the aftertax return on bonds, the government at date 0 chooses the sequences $\left\{c_{1, t}, c_{2, t}\right.$, $\left.n_{1, t}, e_{2, t}, x_{m, t}, x_{u, t}, k_{t+1}\right\}_{t=0}^{\infty}$ to maximize the social welfare function (12) subject to the resource constraint (13), the production of new capital (7), the implementability conditions of the workers (14) in each period, the life-time implementability condition of the capitalists (15), the decentralization condition (11) in each period, and the upper bound on capital tax rates (16). In our economy, the upper bound on capital tax rates (16) does not bind provided a sufficient distortion on intangible investment which is needed to build capital.

The Lagrangian and the resulting first-order conditions are relegated to the "Appendix". Combining the optimality conditions from the Ramsey problem with those from the household problem, we obtain the following optimal Ramsey taxes in periods $t \geq 1$ :

$$
\tau_{t}^{n}=1-\frac{Z_{1 c, t}}{Z_{1 n, t}}+\frac{1}{Z_{1 n, t}} \frac{\psi_{t} J_{n, t}^{b}}{f_{n, t} u_{1 c, t}}
$$




$$
\begin{aligned}
\tau_{t}^{d}= & 1-\frac{Z_{2 c, t}}{Z_{2 e, t}}+\frac{\psi_{t+1}}{u_{2 c, t} Z_{2 e, t}}\left(J_{m, t}^{a}-J_{e, t}^{a} \frac{I_{m, t}}{I_{e, t}}\right) \\
& -\frac{\psi_{t}}{u_{2 c, t} Z_{2 e, t}}\left(J_{m, t}^{b}-J_{e, t}^{b} \frac{I_{m, t}}{I_{e, t}}\right), \\
\tau_{t}^{k}= & \frac{I_{e, t}}{I_{m, t} Z_{2 e, t} u_{2 e, t}}\left[\psi_{t+1}\left(J_{m, t}^{a}-J_{u, t}^{a}-J_{e, t}^{a} \frac{I_{m, t}}{I_{e, t}}+J_{e, t}^{a} \frac{I_{u, t}}{I_{e, t}}\right)\right. \\
& \left.+\psi_{t}\left(J_{m, t}^{b}-J_{u, t}^{b}-J_{e, t}^{b} \frac{I_{m, t}}{I_{e, t}}+J_{e, t}^{b} \frac{I_{u, t}}{I_{e, t}}\right)\right],
\end{aligned}
$$

where $Z_{j q, t}=\gamma_{j}+\lambda_{j, t}\left(1+\frac{u_{j q q, t} q_{j, t}}{u_{j q, t}}\right), \quad J_{x, t}^{a}=\frac{\partial \frac{u_{2 e, t}}{l_{e, t}}}{\partial x_{t}}$, and $J_{x, t}^{b}=$ $\frac{\partial\left[I_{u, t}\left(f_{k, t}-\delta\right)+I_{m, t} \delta+(1-\delta)\right] \frac{u_{2 e, t}}{I_{e, t}}}{\partial x_{t}}$, with $\phi_{t}, \psi_{t}, \mu_{t}, \lambda_{1, t}$, and $\lambda_{2}$, respectively, denoting the multipliers on (7), (11), (13), (14), and (15). Furthermore, the Ramsey allocation also satisfies $u_{1 c, t} Z_{1 c, t}=u_{2 c, t} Z_{2 c, t}$.

To further characterize the optimal taxes, we consider utility functions of the form:

$$
u_{i}\left(c_{i, t}, n_{i, t}+e_{i, t}\right)=\frac{c_{i, t}{ }^{1-\sigma_{i}}}{1-\sigma_{i}}-\theta_{i} \frac{\left(n_{i, t}+e_{i, t}\right)^{1+\chi_{i}}}{1+\chi_{i}},
$$

where $\sigma_{i}$ is the inverse of the intertemporal elasticity of consumption, $\chi_{i}$ is the inverse of the Frisch labor supply elasticity, and $\theta_{i}$ is the disutility of work for an agent of type $i$, with $e_{1, t}=0$ and $n_{1, t}>0$, and $e_{2, t}>0$ and $n_{2, t}=0$.

From the above Ramsey taxes (17)-(19), it is clear that the optimal tax rates during the transition are affected by the decentralization constraint (11), which involves the marginal gain and marginal cost of producing a new unit of capital. If the decentralization constraint (11) stops binding, i.e., $\psi_{t}=0,{ }^{4}$ the optimal tax rates become

$$
\begin{aligned}
\tau_{t}^{n} & =1-\frac{Z_{1 c, t}}{Z_{1 n, t}} \equiv 1-\frac{\gamma_{1}+\lambda_{1, t}\left(1-\sigma_{1}\right)}{\gamma_{1}+\lambda_{1, t}\left(1+\chi_{1}\right)}, \\
\tau_{t}^{d} & =1-\frac{Z_{2 c, t}}{Z_{2 e, t}} \equiv 1-\frac{\gamma_{2}+\lambda_{2}\left(1-\sigma_{2}\right)}{\gamma_{2}+\lambda_{2}\left(1+\chi_{2}\right)}, \\
\tau_{t}^{k} & =0 .
\end{aligned}
$$

In addition, we find $u_{1 c, t}\left[\gamma_{1}+\lambda_{1, t}\left(1-\sigma_{1}\right)\right]=u_{2 c, t}\left[\gamma_{2}+\lambda_{1, t}\left(1-\sigma_{2}\right)\right]$. The above findings are consistent with the results of Albanesi and Armenter (2012) as there are no permanent intertemporal distortions. Once the decentralization constraint (11) does not bind, the long-run optimal level of the corporate income tax is zero while the optimal level of the labor (dividend) income tax depends on the Pareto weight on workers (capitalist), the preference parameters of the workers (capitalists), and the distortionary cost of taxation levied on the workers (capitalists). To further characterize the optimal taxes during the transition and in the long run, we resort to numerical methods.

\footnotetext{
4 In our numerical exercise, we find that the decentralization constraint (11) does not bind in the long run.
} 


\subsection{Numerical characterization}

In this section we provide a numerical assessment of the timing of the optimal corporate, dividend and labor tax rates presented in the previous section and compare them with the timing of the optimal tax rates in an economy with no intangible investment.

First, we assume specific functional forms. For the utility functions, we assume (20). For the technology function, we assume a Cobb-Douglas production function:

$$
f\left(k_{t}, n_{t}\right)=A k_{t}^{\alpha} n_{t}^{1-\alpha},
$$

with $A>0$, and $\alpha \in(0,1)$, and a general investment function that takes the form of a nested CES:

$I\left(x_{m, t}, x_{u, t}, e_{2, t}\right)=B\left[\mu_{m} x_{m, t}^{\rho_{m}}+\left(1-\mu_{m}\right)\left(C\left[\mu_{u} x_{u, t}^{\rho_{u}}+\left(1-\mu_{u}\right) e_{2, t}^{\rho_{u}}\right]^{\frac{1}{\rho_{u}}}\right)^{\rho_{m}}\right]^{\frac{1}{\rho_{m}}}$,

with $B, C>0$, and $\mu_{m}, \mu_{u} \in(0,1)$.

In our calibration, we consider a period to be the equivalent to 1 year. In terms of parameter values, we consider the following. In accordance with McGrattan and Prescott (2005), we assume the population is composed of $90 \%$ workers, i.e., $\kappa_{1}=$ 0.90 , and $10 \%$ capitalists, i.e., $\kappa_{2}=0.10$. We assume preference parameters are the same between workers and capitalists. For both, we assume $\log$ utility $\left(\sigma_{1}=\sigma_{2}=1\right)$, and a Frisch labor supply elasticity of 0.75 consistent with Chetty et al. (2012), i.e., $\chi_{1}=\chi_{2}=1.33$. In the calibration, we target $\theta_{1}=\theta_{2}$ to yield $n_{1}=0.33$ at the initial steady state. Both types of agents also share the same discount factor $\beta$, equal to 0.98 , and consistent with an annual interest rate of $2 \%$.

In the final good production function, we set total factor productivity as $A=4$ for computational convenience. We choose an income share of capital equal to $\alpha=0.40$ to target a consumption ratio of $\frac{c_{2, s s}}{c_{1, s s}}=3.0$ in accordance with Aguiar and Bils (2015). The depreciation rate is set to $\delta=0.08$ to take account of both tangible and intangible investments. ${ }^{5}$ For the investment function, we set $\rho_{m}=-0.50$ to consider some complementarity between tangible resources $x_{m, t}$ and the composite of intangible resources and management time. We set $\rho_{u}=0.25$ to allow for some substitutability between intangible investment, $x_{u, t}$, and management time, $e_{2, t}$, and later perform sensitivity with respect to this parameter. Then we calibrate $B$ and $\mu_{m}$ to match an investment to capital ratio of $\frac{x_{m, s s}+x_{u, s s}}{k_{s s}}=0.037$, consistent with Asker et al. (2015), and a capital to output ratio of $\frac{k_{s s}}{f\left(k_{s s}, n_{s s}\right)}=2.73$, consistent with McGrattan and Prescott (2005) estimations. The parameter $\mu_{u}$ is set to 0.15 , and $C$ is calibrated to target the hours devoted to management time by capitalists, $e_{2, s s}=0.33$.

We assume that the economy starts off at an initial steady state. That initial steady state considers a government policy characterized by a government spending to output ratio of $19 \%$, a labor income tax rate of $31.6 \%$, a dividend income tax rate of $29.1 \%$, and a corporate income tax rate of $35 \%$.

\footnotetext{
5 Here we assume that tangible capital depreciates at a rate equal to 6.7 while intangible depreciates at a $10 \%$ rate.
} 
Table 1 Parameter values and initial steady-state allocation and welfare

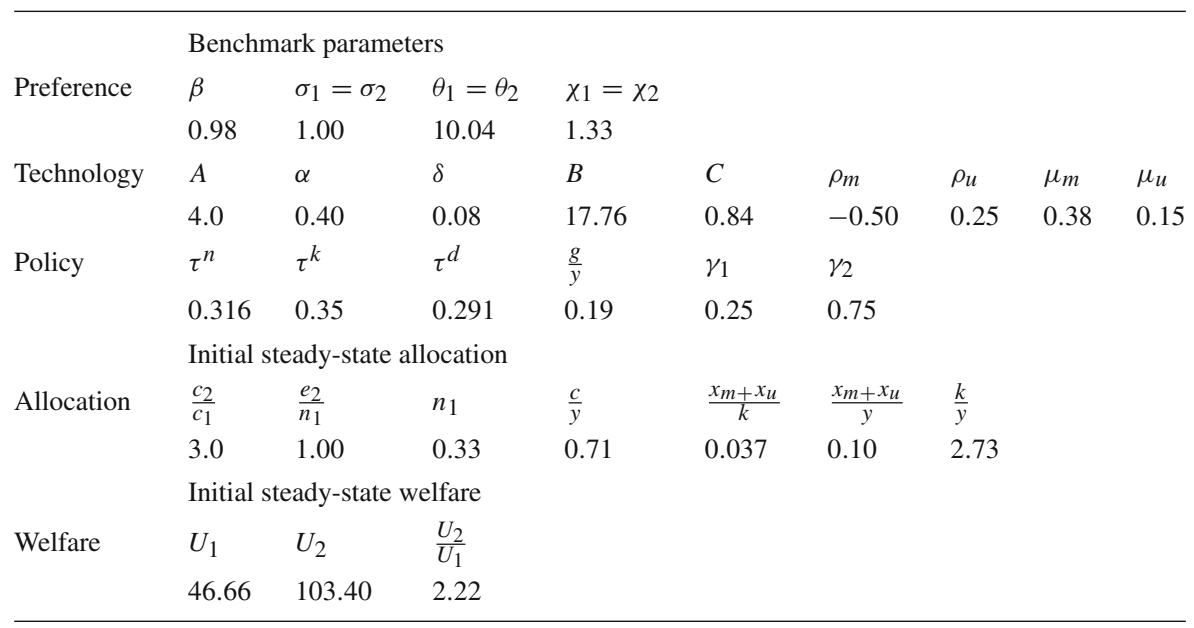

Table 1 summarizes the parameter values and the initial steady-state allocation and welfare for our benchmark calibration.

For the economy with no intangible investment, we assume $\mu_{u}=0$ in the general formulation of the investment function. That reduces our investment function to:

$$
I\left(x_{t}, e_{2, t}\right)=B\left[\mu x_{m, t}^{\rho}+(1-\mu) e_{2, t}^{\rho}\right]^{\frac{1}{\rho}},
$$

with $\rho=-0.50$, consistent with our previous parameterization. The parameters $B$ and $\mu$ are calibrated to match an investment to capital ratio of $\frac{x_{m, s s}}{k_{s s}}=0.037$, and a capital to output ratio of $\frac{k_{s s}}{f\left(k_{s s}, n_{s s}\right)}=1.65$, consistent with those in an economy with no intangibles. The depreciation rate of capital $\delta$ is set to $6.7 \%$. In addition, the capital share is calibrated to match $\frac{c_{2, s s}}{c_{1, s}}=3.0$ in the initial steady state, which yields $\alpha=0.44$.

For both economies, all functions and parameters are now chosen, except for the Pareto weights on workers and capitalists. For $\sigma_{1}=\sigma_{2}=1$, the following optimality condition from the Ramsey problem $u_{1 c, t}\left[\gamma_{1}+\lambda_{1, t}\left(1-\sigma_{1}\right)\right]=$ $u_{2 c, t}\left[\gamma_{2}+\lambda_{1, t}\left(1-\sigma_{2}\right)\right]$, can be written as $\frac{c_{2, t}}{c_{1, t}}=\frac{\gamma_{2}}{\gamma_{1}}$. Then to consider a Paretoimproving reform we choose the Pareto weights so as to keep the consumption ratio at the same level as in the initial steady state, i.e., $\frac{c_{2, t}}{c_{1, t}}=3.0$, which implies $\gamma_{1}=0.25$ and $\gamma_{2}=0.75$. As welfare is also affected by labor and time management choices, we later check that these Pareto weights are consistent with a Pareto-improving reform.

We assume then that our Ramsey tax reform takes place at that initial steady state. The results of this numerical exercise are reported below.

The timing of the optimal corporate tax rate is presented in Fig. 1. Without intangible investment, the Ramsey corporate tax is set to the upper bound of $100 \%$ for 10 years, and then after a 1 year with $83 \%$ taxation, corporate taxes fall to $0 \%$ permanently. In contrast, with intangible investment, the Ramsey corporate tax is initially set to $-20 \%$, 


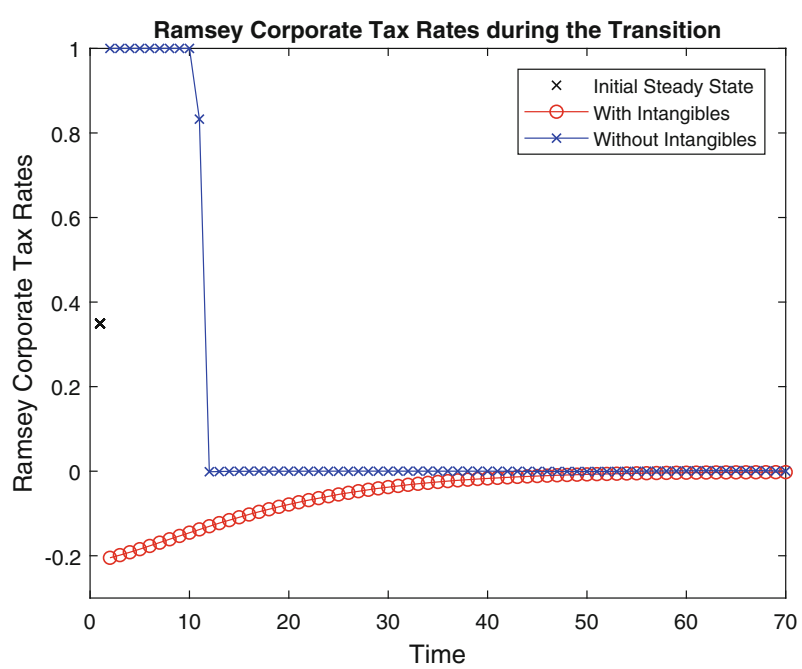

Fig. 1 Ramsey corporate tax rates during the transition

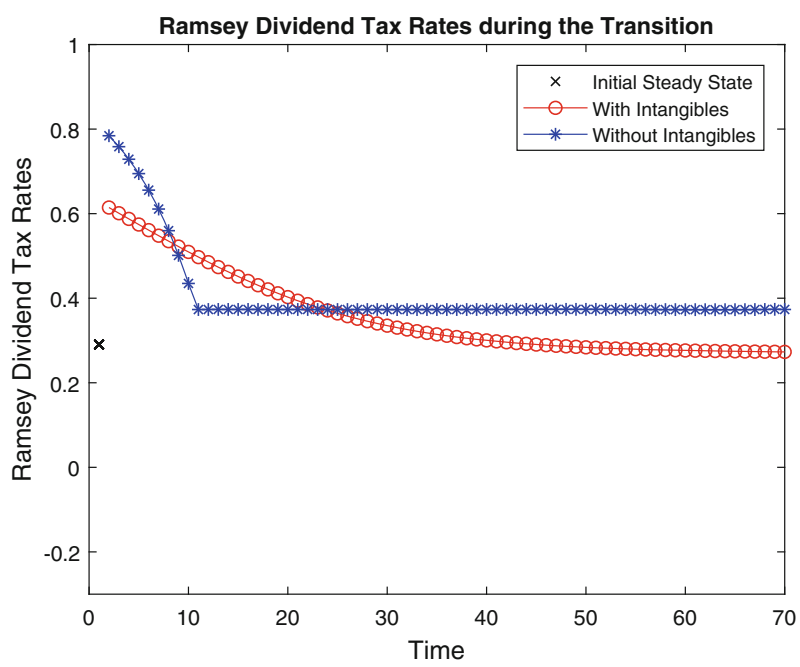

Fig. 2 Ramsey dividend tax rates during the transition

and from then on the optimal corporate tax follows a slow convergence toward zero that takes 50 years, approximately.

Figure 2 presents the timing of the optimal dividend tax rate. Without intangible investment, the Ramsey dividend tax is set to $78 \%$ initially and falls sharply toward $37 \%$ over 10 years. With intangible investment, however, the Ramsey dividend tax is initially set to $61 \%$ and from then on the optimal dividend tax follows a slow and smooth decline toward $27 \%$ that again takes around 50 years.

In Fig. 3 we depict the timing of the optimal labor tax rate. Without intangible investment, the Ramsey labor tax falls to zero initially and converges to $-2 \%$ in 


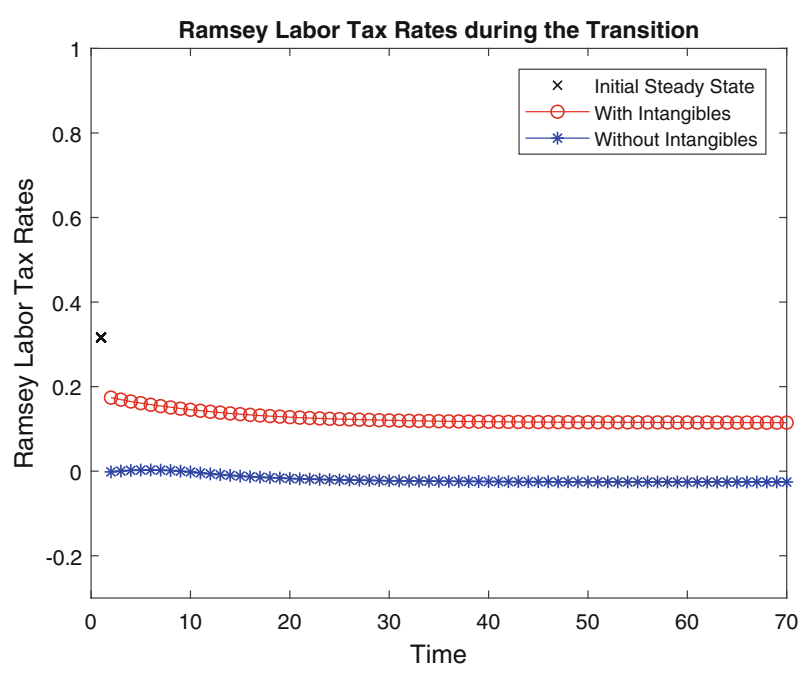

Fig. 3 Ramsey labor tax rates during the transition

the long run. The presence of intangible investment does not affect the timing of the optimal labor tax rate, but affects the level. With intangible investment, the Ramsey labor tax rate is set to $17 \%$ initially and converges to $11 \%$ in the long run.

All in all, we see that when we abstract from intangible capital, the optimal fiscal policy is a confiscatory tax on corporate income (a little bit less so for dividends) for as long as necessary, together with the immediate elimination of labor income taxes. This happens even in a world where the planner puts three times more weight on the welfare of each capitalist than on the welfare of each worker.

In contrast, when we consider intangible capital, confiscatory taxation of corporate income becomes very distortionary. In such a world, the optimal fiscal policy is radically different, with a reduction of corporate income taxes on impact (turning it into a $20 \%$ subsidy), and then a long time period until it converges to zero, together with an increase in dividend taxes (not as large as in the case without intangibles) and then it is progressively reduced. Labor income taxes are reduced but not eliminated, both in the short run and in the long run.

Additionally, we explore the effect of intangibles on the Ramsey allocation.

Figure 4 shows that intangible investment has very little effect on the capital output ratio. Relative to the initial steady state ratio, the capital output ratio is lower without intangibles than with intangibles.

Figure 5 depicts the investment to output ratios relative to their respective initial steady-state values. Both tangible and intangible investment increase on impact for both economies, with and without intangibles. However, the timing of tangible investment is affected by the presence of intangibles. Without intangibles, tangible investment to output increases for around 10 years and then declines toward its steadystate value, while, with intangibles, the tangible investment to output ratio follows a slow decline toward its steady state. 


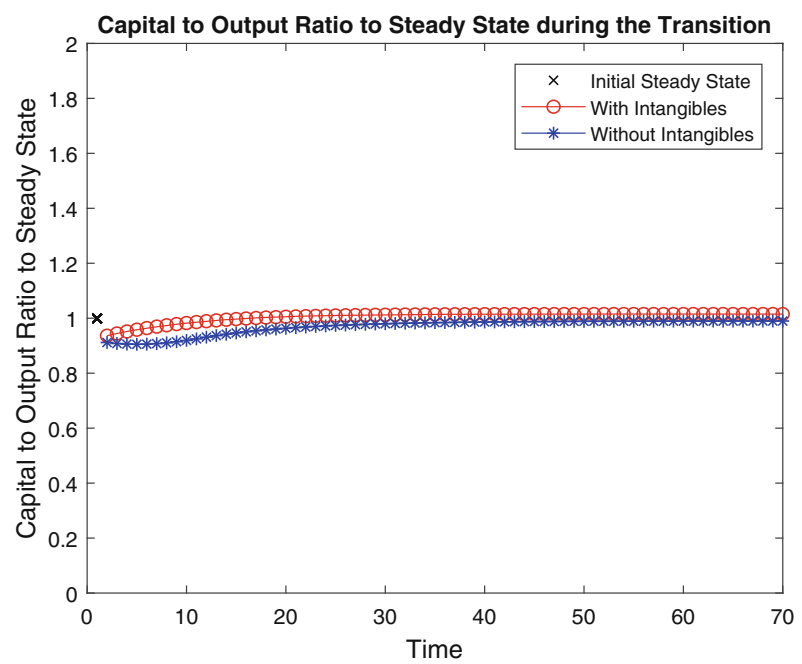

Fig. 4 Capital to output relative to initial steady state

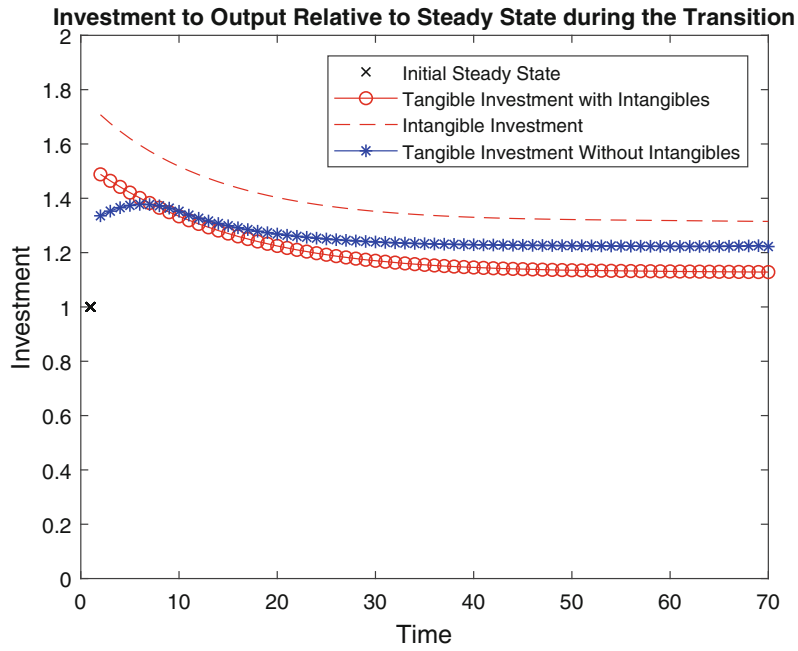

Fig. 5 Investment to output relative to initial steady state

Figure 6 presents the Ramsey allocation of labor and effort. We find that the presence of intangibles affects the level of labor, but not the timing of the optimal labor supply. However, intangibles do affect the allocation of time management during the transition. Without intangibles, time management increases steeply and quickly toward its steady state, while with intangibles, the optimal time management follows a rather flat and slow increase toward its long-run value.

In addition, we perform sensitivity analysis with respect to the curvature between intangible investment, $x_{u, t}$, and management time, $e_{2, t}$. In our benchmark, we assume 


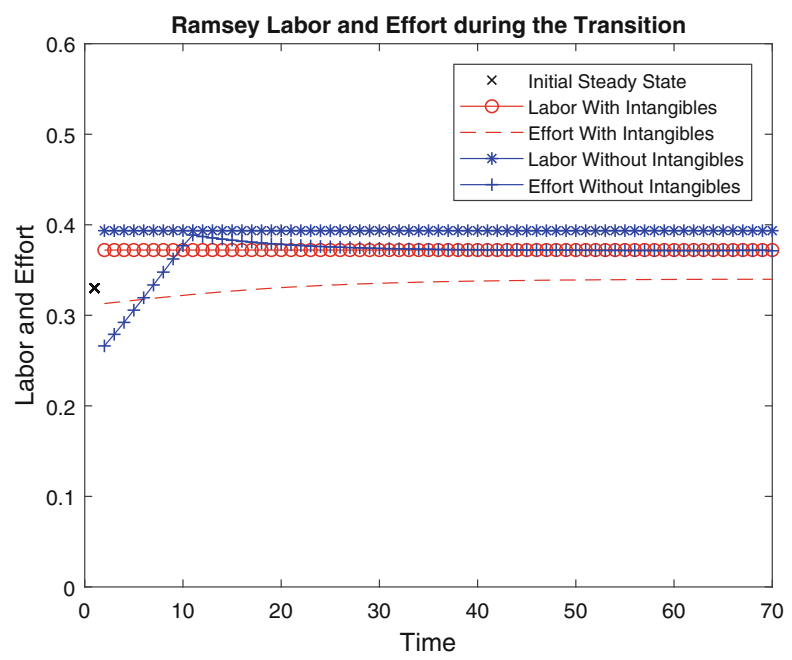

Fig. 6 Labor and effort during the transition

that these variables are rather substitutes. Now, for sensitivity purposes, we set $\rho_{u}=$ -0.25 to consider some complementarity between them. The results are presented in Fig. 7a-f.

As shown in Fig. 7a, we find that, with intangibles, the optimal corporate tax falls on impact to $11 \%$ and follows a slow decline toward zero. Therefore, when intangible investment and management time are complements (substitutes), corporate income is taxed (subsidized) during the transition. For this level of complementarity, Fig. 7b, c shows that dividend (labor) income is taxed more (less) than when investment and management time are substitutes. In Fig. 7d, we see that, relative to the initial steady state, now the capital to output ratio is higher without intangible investment. Figure $7 \mathrm{e}$ shows that, when $x_{u, t}$, and $e_{2, t}$ are complementary rather than substitutes, the ratio of intangible capital to output remains below the initial steady-state level rather than above. As shown in Fig. 7f, the optimal levels of labor and effort are not affected very much by the degree of complementarity.

Throughout the numerical analysis, we have focused on Pareto-improving reforms that kept the consumption ratio after the reform at the same level as in the initial steady state, i.e., $\frac{c_{2, t}}{c_{1, t}}=3.0$. That was achieved with the Pareto weights $\gamma_{1}=0.25$ and $\gamma_{2}=0.75$. In our final exercise for sensitivity analysis, we consider a more pro-worker policymaker with Pareto weights equal to $\gamma_{1}=0.75$, and $\gamma_{2}=0.25 .^{6}$ In addition, we allow capitalists to provide raw labor (as if they were workers) if they wish to. This possibility is captured through an additional Kuhn-Tucker condition on the labor choice of the capitalists. The numerical findings are displayed in Fig. 8a-f.

For the new Pareto weights, the Ramsey allocation delivers a consumption ratio of $\frac{c_{2, t}}{c_{1, t}}=1.05$ independently of whether there are intangibles or not. As expected,

\footnotetext{
6 Conesa and Domínguez (2018) reports results for a wider range of Pareto weights in an economy without intangibles.
} 
a Ramsey Corporate Tax Rates

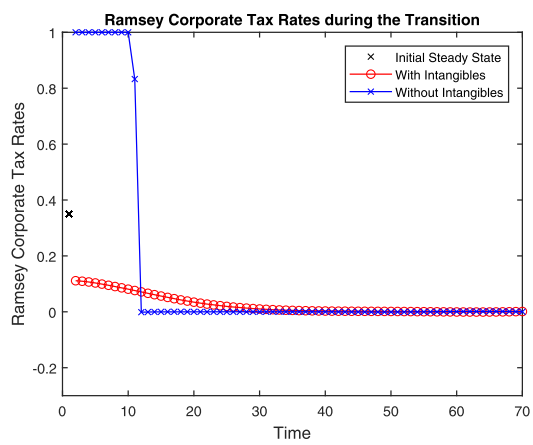

b Ramsey Dividend Tax Rates

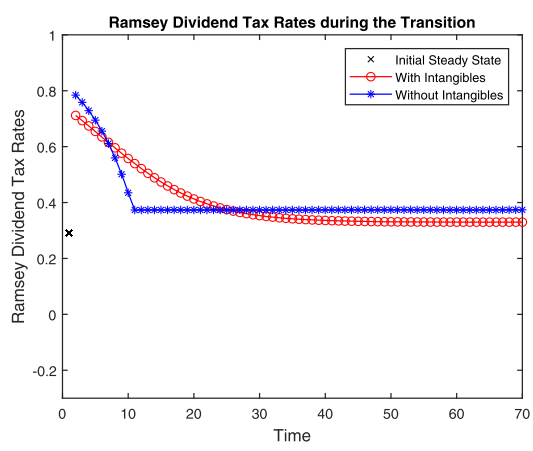

C Ramsey Labor Tax Rates

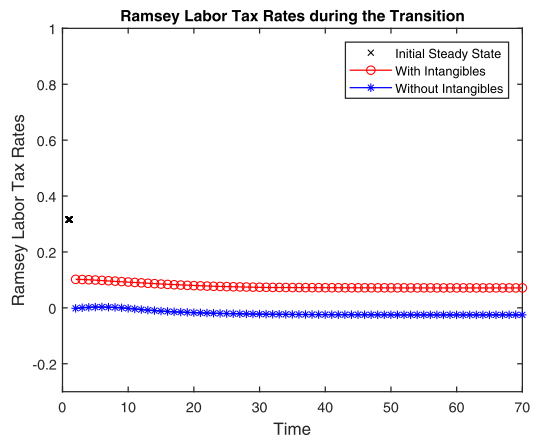

d Ramsey Capital to Output Ratio

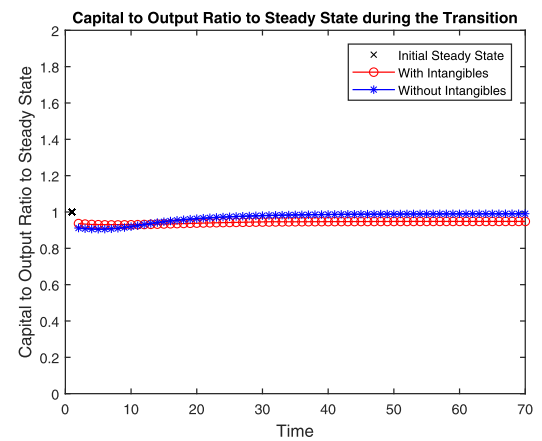

e Ramsey Investment to Output

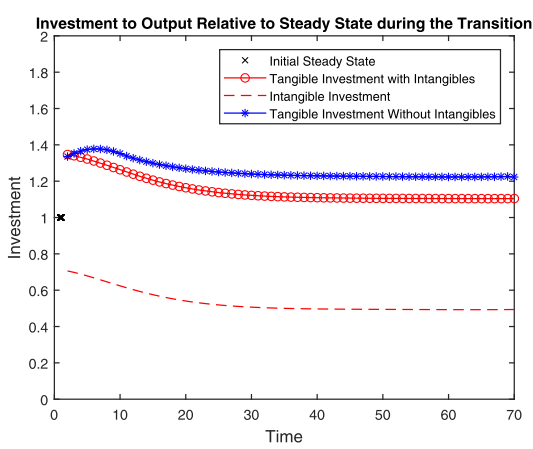

f Ramsey Labor and Effort

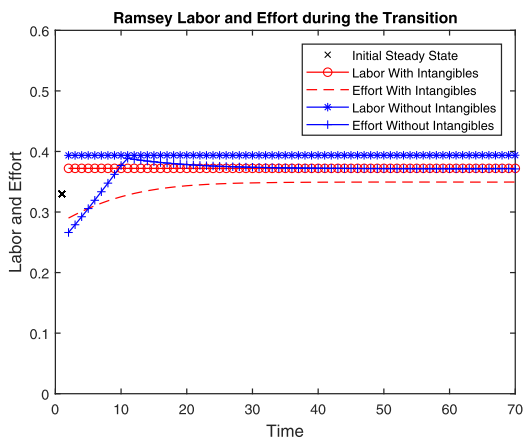

Fig. 7 Ramsey taxes and allocation for $\rho_{u}=-0.25$

Fig. 8a-c shows that now there is more redistribution toward workers. More specifically, without intangibles, optimal corporate tax rates remain at $100 \%$ for more periods, dividend tax rates are larger and converge to $72 \%$ in the long run and labor tax rates provide subsidies along the transition and in the long run (coveraging to $-23 \%$ ). With intangibles, Fig. 8a shows that corporate taxes provide large subsidies (of around 40\%) 
a Ramsey Corporate Tax Rates

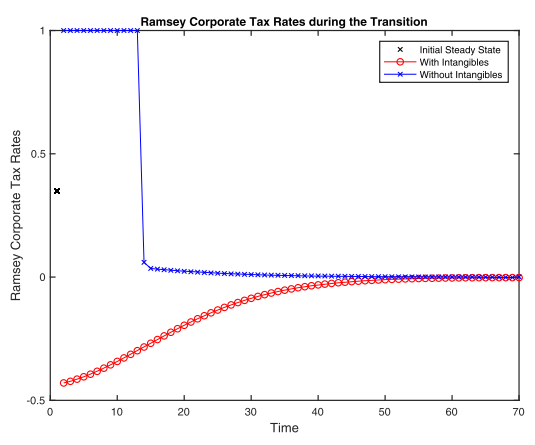

b Ramsey Dividend Tax Rates

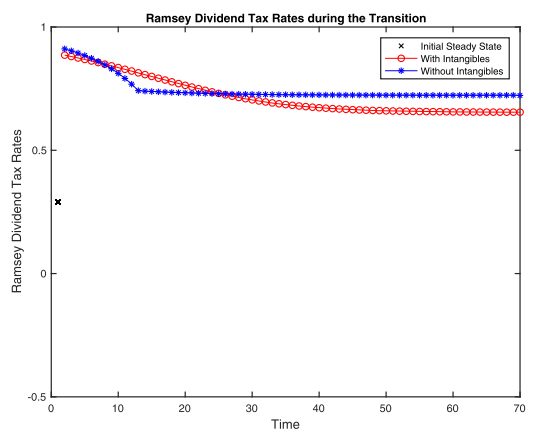

C Ramsey Labor Tax Rates

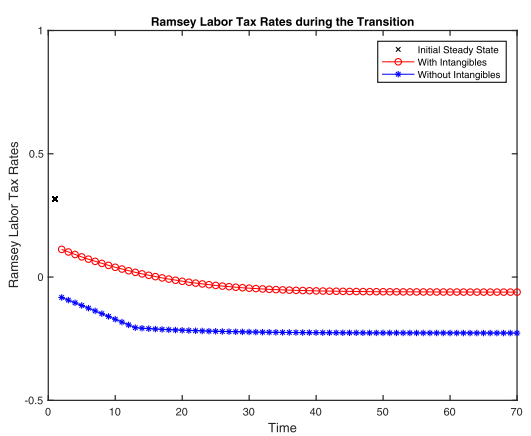

d Ramsey Capital to Output Ratio

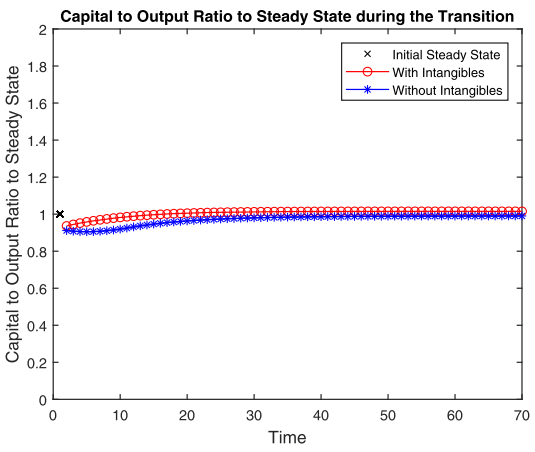

e Ramsey Investment to Output

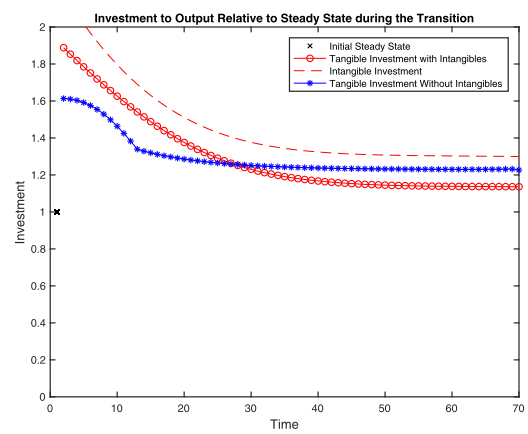

f Ramsey Labor and Effort

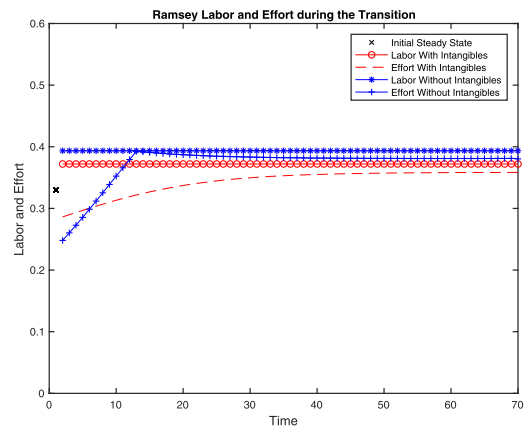

Fig. 8 Ramsey taxes and allocation for $\gamma_{1}=0.75$ and $\gamma_{2}=0.25$

that slowly coverage toward zero in the long run. In Fig. 8b, we see that, with intangibles, most of the redistribution comes through high taxes rates on dividend income (65\% in the long run) and very low and negative taxes on labor income $(-6 \%$ in the long run). As with a lower Pareto weight on workers, the presence of intangibles limits the extent of redistribution through taxation. 


\section{Conclusions}

In this paper we have examined the optimal timing of corporate and dividend tax rates in a Pareto-improving reform and how this timing is affected by the presence of intangible investment. Overall, we find that the presence of intangible investment affects radically the timing of optimal capital taxes. With intangible investment, optimal capital taxes are much lower, smoother and follow a long transition toward their steady-state levels.

Our exercise has considered a Pareto-improving reform in which workers and capitalists all gain in terms of welfare from the tax changes. Our paper suggests that the optimal prescriptions of that reform are very different if the policymaker ignores the effects of intangible investment. Once the policymaker takes into account the effect of intangibles, the degree of confiscatory capital taxation is substantially lower, and therefore the ability to redistribute across agents is severely affected.

There are several limitations to our analysis, among them the assumption of a representative firm. In a world with young growing firms that finance their activities by issuing equity, the fiscal treatment of firm's earnings has additional distortionary impact on the financing of growing firms and thus in their entry decisions, see Gourio and Miao (2010) and Erosa and González (2019).

\section{Compliance with ethical standards}

Conflict of interest The authors declare that they have no conflict of interest.

Ethical standard The authors declare that this research article is in compliance with the ethical standards of SERIEs and our home institutions. The authors do not need an ethical approval as the paper has a purely theoretical content.

Informed consent This article does not contain any information that requires informed consent.

Open Access This article is distributed under the terms of the Creative Commons Attribution 4.0 International License (http://creativecommons.org/licenses/by/4.0/), which permits unrestricted use, distribution, and reproduction in any medium, provided you give appropriate credit to the original author(s) and the source, provide a link to the Creative Commons license, and indicate if changes were made.

\section{Appendix: Ramsey problem}

In this Appendix, we first derive the implementability conditions of the worker and of the capitalist, then we set up the Ramsey problem and derive its first-order conditions.

The per-period implementability condition of the worker is obtained by multiplying the worker's budget constraint (2) by $u_{1 c, t}$ in each period and substituting in the labor income tax rate from the consumption-leisure decision (3), which yields

$$
u_{1 c, t} c_{1, t}+u_{1 n, t} n_{1, t}=0 .
$$


To derive the capitalists' implementability condition, we first multiply the capitalist's budget constraint (5) by $\beta^{t} u_{2 c, t}$, impose $w_{t}=f_{n, t},\left(1-\tau_{t}^{k}\right)=\frac{I_{u, t}}{I_{m, t}}$, and add over time, to get

$$
\begin{gathered}
\sum_{[t=0]}^{\infty} \beta^{t} u_{2 c, t} c_{2, t}+\sum_{[t=0]}^{\infty} \beta^{t}\left(1-\tau_{t}^{d}\right) u_{2 c, t}\left\{\frac{I_{u, t}}{I_{m, t}} x_{u, t}+x_{m, t}\right\} \\
=\sum_{[t=0]}^{\infty} \beta^{t} u_{2 c, t}\left(1-\tau_{t}^{d}\right)\left[\frac{I_{u, t}}{I_{m, t}} f_{k, t}+\tau_{t}^{k} \delta\right] k_{t} \\
+u_{2 c, 0} R_{0}^{b} b_{0}+\sum_{[t=0]}^{\infty} \beta^{t}\left(\beta u_{2 c, t+1} R_{t+1}^{b}-u_{2 c, t}\right) b_{t+1} .
\end{gathered}
$$

We then multiply the investment production (7) by $\beta^{t}\left(1-\tau_{t}^{d}\right) \frac{u_{2 c, t}}{I_{m, t}}$ and add over time to find

$$
\sum_{[t=0]}^{\infty} \beta^{t}\left(1-\tau_{t}^{d}\right) \frac{u_{2 c, t}}{I_{m, t}}\left[k_{t+1}-I\left(x_{m, t}, x_{u, t}, e_{2, t}\right)-(1-\delta) k_{t}\right]=0
$$

We now add (21) and (22) together to obtain

$$
\begin{aligned}
& \sum_{[t=0]}^{\infty} \beta^{t}\left\{u_{2 c, t} c_{2, t}+\left(1-\tau_{t}^{d}\right) u_{2 c, t}\left[\frac{I_{u, t}}{I_{m, t}} x_{u, t}+x_{m, t}-\frac{I_{t}}{I_{m, t}}\right]\right\} \\
& =\left(1-\tau_{0}^{d}\right) \frac{u_{2 c, 0}}{I_{m, 0}}\left[\frac{I_{u, 0}}{I_{m, 0}} f_{k, 0}+\tau_{0}^{k} \delta+1-\delta\right] k_{0}+u_{2 c, 0} R_{0}^{b} b_{0} \\
& \quad+\sum_{[t=0]}^{\infty} \beta^{t}\left\{\beta\left(1-\tau_{t+1}^{d}\right) \frac{u_{2 c, t+1}}{I_{m, t+1}}\left[\frac{I_{u, t+1}}{I_{m, t+1}} f_{k, t+1}+\tau_{t+1}^{k} \delta+1-\delta\right]\right. \\
& \left.\quad-\left(1-\tau_{t}^{d}\right) \frac{u_{2 c, t}}{I_{m, t}}\right\} k_{t+1}+\sum_{[t=0]}^{\infty} \beta^{t}\left\{\beta u_{2 c, t+1} R_{t+1}^{b}-u_{2 c, t}\right\} b_{t+1} .
\end{aligned}
$$

The terms in brackets in the last line become zero after, respectively, imposing the first-order condition for capital (10) and the one for bonds. Next, substituting dividend taxes from the optimality condition (8) in the above equation, we find

$$
\begin{gathered}
\sum_{[t=0]}^{\infty} \beta^{t}\left\{u_{2 c, t} c_{2, t}+u_{2 e, t}\left(\frac{I_{t}}{I_{e, t}}-\frac{I_{u, t}}{I_{e, t}} x_{u, t}-\frac{I_{m, t}}{I_{e, t}} x_{m, t}\right)\right\} \\
=\frac{u_{2 e, 0}}{I_{e, 0}}\left[\frac{I_{u, 0}}{I_{m, 0}} f_{k, 0}+\tau_{0}^{k} \delta+1-\delta\right] k_{0}+u_{2 c, 0} R_{0}^{b} b_{0}
\end{gathered}
$$

which, given $e_{2, t}=\frac{I_{t}}{I_{e, t}}-\frac{I_{m, t}}{I_{e, t}} x_{m, t}-\frac{I_{u, t}}{I_{e, t}} x_{u, t}$, as $I$ is homogeneous of degree 1 , becomes the implementability condition of the capitalist (15). 
The Lagrangian for the Ramsey problem for the government at date 0 is

$$
\begin{aligned}
L= & \sum_{t=0}^{\infty} \beta^{t}\left[\gamma_{1} \kappa_{1} u_{1}\left(c_{1, t}, n_{1, t}\right)+\gamma_{2} \kappa_{2} u_{2}\left(c_{2, t}, e_{2, t}\right)\right] \\
& +\sum_{t=0}^{\infty} \beta^{t} \mu_{t}\left[\kappa_{2} f\left(k_{t}, n_{t}\right)-\kappa_{1} c_{1, t}-\kappa_{2} c_{2, t}-\kappa_{2}\left(x_{m, t}+x_{u, t}\right)-g_{t}\right] \\
& +\sum_{t=0}^{\infty} \beta^{t} \phi_{t} \kappa_{2}\left[I\left(x_{m, t}, x_{u, t}, e_{2, t}\right)+(1-\delta) k_{t}-k_{t+1}\right] \\
& +\sum_{t=0}^{\infty} \beta^{t} \lambda_{1, t} \kappa_{1}\left[u_{1 c, t} c_{1, t}+u_{1 n, t} n_{1, t}\right]+\lambda_{2} \kappa_{2}\left[\sum_{t=0}^{\infty} \beta^{t}\left[u_{2 c, t} c_{2, t}+u_{2 e, t} e_{2, t}\right]-W_{2,0}\right] \\
& +\sum_{t=1}^{\infty} \beta^{t-1} \psi_{t} \kappa_{2}\left[\frac{u_{2 e, t-1}}{I_{e, t-1}}-\beta\left[I_{u, t}\left(f_{k, t}-\delta\right)+I_{m, t} \delta+(1-\delta)\right] \frac{u_{2 e, t}}{I_{e, t}}\right] \\
& +\varsigma_{0} \kappa_{2} \frac{I_{u, 0}}{I_{m, 0}}+\sum_{t=1}^{\infty} \beta^{t} \varsigma_{t} \kappa_{2}\left[-\beta\left[I_{m, t} \delta+(1-\delta)\right] \frac{u_{2 e, t}}{I_{e, t}}+\frac{u_{2 e, t-1}}{I_{e, t-1}}\right],
\end{aligned}
$$

where $\mu_{t}, \phi_{t}, \lambda_{1, t}, \lambda_{2}, \psi_{t}$, and $\varsigma_{t}$, respectively, denote the multipliers on (13), (7), (14), (15), (11) and on $\frac{I_{u, 0}}{I_{m, 0}} \geq 0$ in period 0 and (16) in periods $t \geq 1$. The presence of intangible investment makes corporate taxes distortionary in every period and the upper bound on capital taxes not to bind.

Then the first-order conditions for the Ramsey problem for all periods $t \geq 1$ are

$$
\begin{aligned}
{\left[c_{1, t}\right] } & u_{1 c, t} Z_{1 c, t} & =\mu_{t}, \\
{\left[c_{2, t}\right] } & u_{2 c, t} Z_{2 c, t} & =\mu_{t}, \\
{\left[n_{1, t}\right] } & u_{1 n, t} Z_{2 n, t} & =-f_{n, t} \mu_{t}+\psi_{t} J_{n, t}^{b}, \\
{\left[e_{2, t}\right] } & u_{2 e, t} Z_{2 e, t} & =-I_{e, t} \phi_{t}-\psi_{t+1} J_{e, t}^{a}+\psi_{t} J_{e, t}^{b}, \\
{\left[x_{m, t}\right] } & I_{m, t} \phi_{t} & =\mu_{t}-\psi_{t+1} J_{m, t}^{a}+\psi_{t} J_{m, t}^{b}, \\
{\left[x_{u, t}\right] } & I_{u, t} \phi_{t} & =\mu_{t}-\psi_{t+1} J_{u, t}^{a}+\psi_{t} J_{u, t}^{b}, \\
{\left[k_{t+1}\right] } & \phi_{t} & =\beta \mu_{t+1} f_{k, t+1}+\beta(1-\delta) \phi_{t+1}-\beta \psi_{t+1} J_{k, t+1}^{b},
\end{aligned}
$$

where $Z_{j q, t}=\gamma_{j}+\lambda_{j, t}\left(1+\frac{u_{j q q, t} q_{j, t}}{u_{j q, t}}\right), \quad J_{x, t}^{a}=\frac{\partial \frac{u_{2 e, t}}{I_{e, t}}}{\partial x_{t}}$, and $J_{x, t}^{b}=$ $\frac{\partial\left[I_{u, t}\left(f_{k, t}-\delta\right)+I_{m, t} \delta+(1-\delta)\right] \frac{u_{2 e, t}}{I_{e, t}}}{\partial x_{t}}$.

\section{References}

Abel AB (2007) Optimal capital income taxation. Unpublished Manuscript

Aguiar M, Bils M (2015) Has consumption inequality mirrored income inequality? Am Econ Rev 105:27252756

Anagnostopoulos A, Cárceles E, Lin D (2012) Dividend and capital gains taxation under incomplete markets. J Monet Econ 59:599-611

Albanesi S, Armenter R (2012) Intertemporal distortions in the second best. Rev Econ Stud 79:1271-1307 Armenter R (2007) Time consistent fiscal policy and heterogeneous agents. Rev Econ Dyn 10:31-54 Asker J, Farre-Mensa J, Ljungqvist A (2015) Corporate investment and stock market listing: a puzzle? Rev Financ Stud 28:342-390 
Auerbach AJ (2002) Taxation and corporate financial policy. In: Auerbach AJ, Feldstein M (eds) Handbook of public economics, vol 3. Elsevier, Amsterdam, pp 1251-1292

Bassetto M (2014) Optimal fiscal policy with heterogeneous agents. Quant Econ 5:675-704

Chamley C (1986) Optimal taxation of capital income in general equilibrium with infinite lives. Econometrica 54:607-622

Chari VV, Nicolini JP, Teles P (2016) More on the optimal taxation of capital. Unpublished Manuscript

Chetty R, Guren A, Manoli D, Weber A (2012) Does indivisible labor explain the difference between micro and macro elasticities? A meta-analysis of extensive margin elasticities. NBER Macroecon Annu 27:1-56

Conesa JC, Domínguez B (2013) Intangible investment and Ramsey capital taxation. J Monet Econ 60:983995

Conesa J. C, Domínguez B (2018) Capital taxes and redistribution: the role of management time and tax deductible investment. Stony Brook working paper series, 18-10

Erosa A, González B (2019) Taxation and the life cycle of firms. J Monet Econ (forthcoming)

Gourio F, Miao J (2010) Firm heterogeneity and the long-run effects of dividend tax reform. Am Econ J Macroecon 2:131-168

Judd KL (1985) Redistributive taxation in a simple perfect foresight model. J Public Econ 28:59-83

Lev B (2018) Intangibles. SSRN working papers

McGrattan ER, Prescott EC (2005) Taxes, regulations and the value of U.S. and U.K. corporations. Rev Econ Stud 72:767-796

Peters R, Taylor L (2017) Intangible capital and the investment-q relation. J Financ Econ 123:251-272

Straub L, Werning I (2018) Positive long run capital taxation: Chamley-Judd revisited. Unpublished Manuscript

Strulik H, Trimborn T (2012) Laffer strikes again: dynamic scoring of capital taxes. Eur Econ Rev 56:11801199

Publisher's Note Springer Nature remains neutral with regard to jurisdictional claims in published maps and institutional affiliations. 